\title{
Zinc-Binding, DNA-Binding Motif
}

National Cancer Institute

\section{Source}

National Cancer Institute. Zinc-Binding, DNA-Binding Motif. NCI Thesaurus. Code

C13427.

Zinc-binding, DNA-binding motifs in proteins contain amino acids that are folded into a single DNA-binding structural unit around a zinc atom. 